\title{
CIRCULUS PENDENS ANTE TABERNAM
}

\author{
Ángel Muñoz García \\ Universidad del Zulia. Maracaibo. \\ Venezuela
}

\section{RESUMEN}

El saber clerical aparece como un bien instrumental, más que como un bien en sí, en la literatura destinada a los clérigos que cuidan de las iglesias. La adquisición de conocimientos en la Edad Media está justificada y condicionada por el puesto que cada cual ocupa en la Iglesia y en la sociedad. La expresión saber latín o ser gramático resume las exigencias para ser clérigo.

\begin{abstract}
The use of the circle to signify wine was common medieval logicians. The author of this article studies the true sense in which those masters used it, making use of literature and the work of great logicians, such as Albert of Saxony and William of Ockham, to do so.
\end{abstract}

Es conocido el ejemplo de signo aducido por los lógicos medievales: el círculo, como signo del vino. Aparte de los matices de la picaresca goliarda que sugiere, resulta intrigante en cuanto al verdadero sentido que los maestros pretendían darle al utilizarlo.

En la Edad Media, los juglares entretenían ciudades y castillos con sus cantos y representaciones. El pago por ello frecuentemente era en especie: comida, ropas y -sobre todo- vino; es conocido, por ejemplo, cómo solían concluir, terminado de recitar el Cantar de Mio Cid:

\author{
El romanz es leído \\ dadnos del vino; \\ si no tenéis dineros \\ echad allá unos peños, \\ que bien nos lo darán sobre ellos.
}

Ante el mester de ioglaría, el clero no quiso quedar atrás. Con pretensiones de culto, en latín, e incluso en lengua vernácula, crea su mester de clerecía. Y esperando recompensa, 
como los juglares; pero no, como quizá cabría esperar en este caso, una recompensa más espiritual, sino tan espirituosa como la de sus colegas seglares: ${ }^{1}$

Quiero fer una prosa en roman paladino

En qual suele el pueblo fablar a su vezino

ça non so tan letrado por fer otro latino;

Bien valdrá, como creo, un vaso de bon vino.

Por aquello de el vino alegra el corazón del hombre, el canto a la bebida, a la comida y al erotismo se justifican en la literatura. Los Milagros de Nuestra Señora, del español Berceo y del francés Gauthier de Coincý, se realizan a veces en favor de clérigos tan llenos de vicios como los seglares: así, en El clérigo y la flor, El sacristán impúdico, El monje y S. Pedro, El prior y el sacristán, El clérigo embriagado, La Abadesa encinta, ${ }^{2}$ El milagro de Teófilo.

Simbiosis de juglar y clérigo, con la mayor malicia que una mayor ilustración proporciona sobre la ingenuidad juglaresca, estaban también los goliardos. Clérigos, estudiantes exmonjes, de vivir errático, sin trabajo, sin dinero y con marcada tendencia a los placeres de la cama y del buen comer y beber. Otros, de mejor posición social, monjes, abades y obispos, se hacen pasar - como recurso literario- por goliardos: el canónigo García de Toledo en el s. XI; Baudri de Mennsur-Loire abad de Bourgueil y arzobispo de Dol en Bretaña; Pedro de Blois, archidiácono de Bath en la segunda mitad del s. XII; Marbod, obispo de Rennes en 1096 y que muere benedictino en 1123; Gautier de Chatillon; el más conocido Juan Ruiz, Arcipreste de Hita; son algunos ejemplos.

Escribiendo sin artificios, con desenfadada naturalidad, les cabe el mérito de haber llevado la poesía latina a su más expresiva vitalidad, y sustituir en ella la métrica antigua por el rítmo y la rima.

Prescindiendo de otras inclinaciones non sanctas, limitémonos a su afición por el buen vino: ${ }^{3}$

En tercer lugar, canto a la taberna;

quisiera nadar en esa cisterna, donde el suave vino junto a mí discierna

hasta que me canten «requiem aeternam».

1 Berceo, Vida de Sto. Domingo de Silos, 2. ${ }^{\mathrm{a}}$ estrofa.

2 Relato miniado a página entera en las Cantigas de Alfonso X. (cfr. ms. Escorial, t. I, 1).

3 «Tertio capitulo memoro tabernam, / illam nullo tempore sprevi neque spernam, / donec sanctos angelos venientes cernam, / cantantes pro mortuis "Requiem aeternam". / Meum est propositum in taberna mori, / ut sint vina proxima morientis ori. / Tunc cantabunt laetius angelorum chori / "Sit Deus propitius isti potatori". / Uncuique proprium dat Natura donum. / Ego versus faciens bibo vinum bonum / et quod habent purius dola cauporum. / Tale vinum generat copiam sermonum. / Tales versus facio quale vinum bibo / nihil possum facere nisi sumpto cibo, / nihil valet penitus quae ieiunus scribo. / Nasonem post calicem carminem preibo». (Carmina Burana, ed. J. Schemeller, Stuttgart, 1847, n. 191). Nos hemos permitido en ésta y en la nota 4 adaptar al castellano los versos latinos. 
Tanto verso escribo, cuanto vino bebo; no puedo inspirarme si el vaso no elevo. Si camino sobrio, apenas me muevo; siempre tengo cerca vasos de relevo.

En toda mi vida, más que al pobre Job, cantaré al Patriarca que el vino inventó; hasta que los ángeles canten a una voz: «Dios sea propicio a este bebedor».

Aunque la Iglesia reprime de continuo sus acciones, ${ }^{4}$ los goliardos insisten: ¿De qué extrañarse?, parecen decir. ¿Por qué nos recriminan? No somos los únicos con tales gustos: ${ }^{5}$

\author{
Bebe el rústico, el letrado, \\ el galán, el jorobado. \\ Bebe el soldado y el clero, \\ exiliados, forasteros. \\ Bebe el sano y el leproso, \\ el veraz y el mentiroso. \\ Bebe el creyente, el gentil; \\ beben cien y beben mil. \\ Bebe el blanco, bebe el negro. \\ Bebe la abuela y el suegro, \\ la señora y el esposo, \\ el amante y el celoso. \\ Bebe la hermana, el hermano, \\ bebe el niño y el anciano. \\ Bebe el siervo y la doncella; \\ bebe aquél y bebe aquélla. \\ Bebe el juez, el abogado, \\ el fiscal y el magistrado. \\ Bebe el enfermo y el sano, \\ el Rector con el Decano. \\ Bebe el amo y el señor;
} 1281.

4 P. ej., los concilios de Tréveris, en 1227, de Rouen y Chateau Gonthier, en 1231, de Salzburgo, en

5 «Bibit hera, bibit herus, / bibit miles, bibit clerus, / bibit ille, bibit illa, / bibit servus cum ancilla; / bibit velox, bibit piger, / bibit albus, bibit niger, / bibit constans, bibit vagus, / bibit rudis, bibit magus. / Bibit pauper et aegrotus, / bibit exul et ignotus; / bibit puer, bibit canus, / bibit praesul et decanus; / bibit soror, bibit frater / bibit anus, bibit mater, / bibit ista, bibit ille, / bibit centum bibunt mille». (Carmina Burana, n. 196). 
el estudiante, el Doctor.

Bebe el pobre, bebe el rico, el Abad y el Dominico.

La picaresca goliarda no sólo penetró la literatura. En la vida misma de monasterios, colegios y universidades, el vino tuvo lugar de preferencia. En el Colegio de la Sorbona, los estudiantes o maestros negligentes en participar en las disputas escolares eran multados con privación de vino. ${ }^{6}$ Igualmente, los monjes impuntuales o los que se negaran al trabajo de copistas. ${ }^{7}$ Entre éstos son frecuentes los que, en los colofones y al modo de Berceo, solicitan como recompensa por su trabajo un vaso de buen vino. ${ }^{8}$ Algún monje o goliardo nos dejó su protesta en un grafitti de la época en la bodega del Monasterio:"

Bonum vinum cum odore

Bibit Abbas cum Priore;

Datur aqua Fratribus.

Los vinos monacales fueron tan famosos que hasta se eligió la expresión vinos teológicos para denominarlos. En el condado de Ribagorza, al pie de los Pirineos españoles, existió el monasterio de San Pedro de Taberna, objeto de no pocos privilegios de los reyes navarros.

No extrañe, pues, que el vino se introdujera hasta en los escritos filosóficos, al menos en los de Lógica, la ciencia que busca la verdad. In vino veritas. No menos de nueve veces — por poner un caso- le sirve a Alberto de Sajonia en su Perutilis Logica para ejemplificar. ${ }^{10}$

Con especial insistencia, el vino aparece como ejemplo de signo. Ejemplo que se resume en que el círculo es signo del vino. "Hecho sin mayor transcendencia; pero de cómo se interprete el ejemplo (cuál sea la relación círculo-vino) puede depender la noción misma del signo.

Nuestra curiosidad parte de Ockham: «así la voz significa naturalmente, como todo efecto significa al menos a su causa; como también el círculo significa al vino en la

6 Estatuto relativo a las disputas, de 14 de noviembre de 1344: cfr. Glorieux, P., Aux origines de la Sorbonne I, Paris, 1966, pp. 224 ss.

7 Cfr. Regla S. Benito, c. 43, 13-17, ed. Colombás-Aranguren, Madrid, 1979, p. 142. Qui scribere scit, et potest, et noluerit, a vino abstineatur arbitrio Prioris: estatuto de 1279, de la cartuja: cit. por Roover, F., The Scriptorium, en J. Thompson, The Medieval Library, New York, 1957, p. 601.

8 Puede verse, al respecto, Muñoz García, A., Libros y Editores Medievales, Revista de Filosofía, 15 , Maracaibo, 1991, p. 114.

9 «El buen vino, aromático, lo bebe el abad con el prior; y a los frailes les dan agua».

10 Alberto de Sajonia, Perutilis Logica, ed. Á. Muñoz García, México, 1988: appeto vinum: n. 513; bis bibisti vinum: n. 518; bibo vinum, ergo vinum est: $n$. 587; tu potasti heri vinum: $\mathrm{n}$. 614 ; tantum homo movetur in taberna: $\mathrm{n} .789$; vinum dulce est in cellario meo: $\mathrm{n}$. 1164; rex non potest portare quartam vini: $\mathrm{n} .1419$; vinum hamatur: n. 1573; Deus creavit vinum invite: n. 1574.

11 Además de los diferentes textos que se irán citando, véanse también: Kilwardby. Super Prinscianum Maiorem, ed. Fredborg, Green-Pedersen, Nielsen, Pinborg, Cahiers de l'Institut du Moyen Âge Grec et Latin, 15. 1975, p. 56; Duns Scoto, Quaestiones super Libros Metaphysicorum Aristotelis, VI. q. 8. 
taberna». ${ }^{2}$ Por el contexto, cabía la posibilidad de que Ockham estuviera ejemplificando el signo natural. ¿Cuál fue la relación significante círculo-vino?

Cabía interpretarlo como el círculo húmedo que deja la base del vaso en la mesa. Pero no era convincente, pues lo mismo pudiera ser signo de cerveza, agua o cualquier otra bebida. Boehner ${ }^{13}$ alude al círculo del fleje que sujeta las duelas de la cuba de vino; parece más convincente: hay ya una relación entre círculo y vino. Máxime teniendo en cuenta que Ockham --a diferencia de otros anteriores- precisa que se trata del círculo en la taberna, donde el vino se guarda en enormes toneles empotrados en la pared, dejando a la vista su base circular.

Alberto de Sajonia aporta un nuevo dato: el círculo colgado ante la taberna es signo del vino. ${ }^{14}$ Es pues un círculo colgado a la puerta de la taberna. Ello sugiere un signo gremial de taberneros, que anuncia un tipo de negocio. Como aún hoy se anuncian algunos comercios. Aún quedan en ciertas ciudades europeas círculos anunciando expendios de bebidas. Citemos la calle Schmiedgasse y el famoso Plönlein de Rothenbürg ob der Tauber, en Alemania, o el no menos representativo Portalón de Vitoria, en España. Y es frecuente denominar Círculo a ciertas sociedades recreativas o clubs sociales.

Esta interpretación viene confirmada por las Summae Metenses: ${ }^{15}$ «[...] el círculo, por el que sabemos que se vende vino». Y más explícitamente por Roger Bacon:16

el círculo [es signo] del vino, y los artículos de las posadas expuestos en las ventanas de los vendedores, expuestos como signos [...] y todas las cosas por el estilo que se exponen a la vista como signo de que se venden.

Esto aclara a qué círculo se refieren, pero no la relación entre tal círculo y el vino, para que aquél sea signo de éste. Sería una simple asociación de ideas o, a lo más, una relación metonímica. No eran posibles más precisiones que dieran luz sobre la elección del ejemplo, para ilustrar en qué ponían los medievales el fundamento de la relación de significación.

Así las cosas, hubimos de trabajar con el Cursus Philosophicus de Antonio José Suárez de Urbina, ${ }^{17}$ quien en su Logica presenta una variante del ejemplo: ${ }^{18}$ «la rama delante de la

12 «Et sic vox naturaliter significat, sicut quilibet effectus significat saltem suam causam; sicut etiam circulus significat vinum in taberna»: Ockham, Summa Logicae, I, c. 1, ed. Boehner-Gál-Brown, St. Bonaventure, 1974, p. 9.

13 Ockham's Theory of Signification, en Collected Articles on Ockham, St. Bonaventure, 1958, p. 203.

14 «Isto modo dicimus circulum pendentem ante tabernam esse signum vini»: Alberto de Sajonia, Perutilis Logica, ed. cit., n. 15; Quaestiones in Artem Veterem, ed. Á. Muñoz García, Maracaibo, 1988, n. 710.

15 «Ut patet de circulo, per quem vinum venale apprenditur»: ed. L. Rijk, en Logica Modernorum, II-1, Assen, 1967, p. 482.

16 «t circulus vini et res expositae venditionis in fenestris venditorum positae pro signis [...] et omnes res huiusmodi quae in signum venditionis exponuntur»: Roger Bacon, De signis, ed. Fredborg-NielsenPinborg, Traditio, 34, 1978, p. 83.

17 Profesor en Caracas en 1758. La edición de su Cursus Philosophicus se encuentra actualmente en prensa, en base al manuscrito conservado en la Biblioteca Nacional de Caracas.

18 «Unde ramus ante tabernam, sonitus campanae et alia huiusmodi, quamquam proprie significent, nullo modo sunt termini»: Suárez de Urbina, Logica Parva, n. 65 de la edición preparada por el Grupo «Parva Logicalia», actualmente en prensa. 
taberna, el sonido de la campana y otras cosas por el estilo, aunque propiamente significan, en ningún modo son términos». Pensamos en principio en una acomodación localista (sustitución de círculo por rama). Era tentador pensar en la vid. Pero poco probable en una región no vinícola. En verdad, el venezolano no hablaba de rama de la vid, sino simplemente de una rama.

Otro texto, postmedieval, pudo aclarar algo: el Breviarium Logicae de Iodocus Trutvetter dice sobre el signo en general: ${ }^{19}$ «Se llama signo en cuanto lo usamos para significar algo, como el círculo delante de la taberna». Y al dividirlo en natural y convencional, precisa sobre éste: ${ }^{20}$ «así también el círculo verde o la bandera colgado de la taberna es signo del vino o de la cerveza venal». No es pueș cualquier círculo, sino expresamente uno verde, o una rama circular. Y entre las invectivas de Luis Vives contra los medievales, encontramos la frase «si la corona que cuelgan en las tabernas es de hiedra». ${ }^{21} \mathrm{Al}$ menos, se aclaraba el ejemplo de Suárez de Urbina.

La confirmación a todo esto es un Pontifical de Sens, ${ }^{22}$ cuyo miniaturista representó la famosa feria del Lendit, taberna incluida, en cuyo frente se distingue el círculo, hecho con una rama, a juzgar por las hojas que se destacan claramente del perímetro circular. Bastantes años más tarde, las tabernas así identificadas seguirán apareciendo en las pinturas de Brueghel.

Las coronas vegetales estuvieron vinculadas desde la antigüedad a la excelencia y perfección. Inicialmente adjudicadas a los dioses por los griegos, ${ }^{23}$ pasaron luego a ser galardón de los héroes: los vencedores de los Juegos Î́stmicos, Nemeos, Píticos y Olímpicos eran coronados con pino, apio, laurel y olivo («no es ya un hombre; es un dios», diría Homero): sólo estos atletas y los magistrados eran stefanóforos, portadores de tales coronas. Entre los romanos, Domiciano se coronaba de oro para presidir los Juegos Capitolinos; la corona triunfal, de laurel, premiaba al general que regresaba triunfador a Roma; la corona cívica, de encina o roble, a quien salvaba la vida de un conciudadano.

Dionisos o Baco, dios del vino, que luchó en apariencia de león contra los Gigantes, era representado provisto de cuernos (símbolo de fuerza y poder) en carro tirado por tigres y leones, coronado de hiedra. Era llamado Liber, en alusión al tronco de la vid y al carácter liberador y de arrobamiento del vino. Por lo mismo, los romanos coronaban a los comensales con hiedra (corona convivialis), de la que se creía que absorbía los humores del vino, haciéndose así trepadora.

Es claro, pues, el uso de la hiedra como signo del vino. Pero ningún texto medieval hablaba de ella. Sólo Vives, el humanista fiel a los clásicos. Los demás la sustituyeron por el círculo, sin que quedara claro el motivo y la vinculación significante círculo-vino.

19 «Dicitur autem signum in quantum ipso utimur ad significandum aliquid, ut circulus amte tabernam»: Iodocus Trutvetter, Breviarium Logicae, edición de Erfurt, sin fecha (hacia 1500). Ejemplar de la Biblioteca Amploniana, Pl. 206.

20 «Sic quoque circulus viridis vel vexillum pendens ex taberna est signum vini vel cerevisiae venalis».

21 Las disciplinas: III, De la corrupción de la Dialéctica, c. 5.

22 Paris, BN, lat. 962, f. 264 (siglo XIV).

23 Por no citar sino las más usadas, y aplicadas a los dioses más relevantes: la de encina a Júpiter, de laurel a Apolo, de mirto a Venus, de olivo a Minerva, de álamo a Hércules, de encina y vid a Rea... 
El círculo, una de las imágenes elementales del hombre, tuvo siempre peso semántico, por su vinculación a la idea de perfección; lo vemos en pinturas rupestres, círculos de menhires y representaciones del universo. El círculo de oro representaba entre los romanos la dignidad patricia. En el círculo se basa el coronis, signo tironiano con el que los copistas indican el fin de su escrito. «La línea circular es más perfecta que toda otra», afirmará Sto. Tomás. ${ }^{2+}$ Me salió redondo, afirmación rotunda y otras, son expresiones aún hoy usuales. Por antítesis, círculo vicioso es el peor y más vergonzoso error para un dialéctico. Y verde es lo vigoroso, fuerte, robusto. El círculo verde - vigor y perfección— resulta, así, preciso para representar el vigor y euforia producto del vino y la esfera espiritosa de la embriaguez. Más aún, un círculo de hiedra, siempre verde, trepadora y en ascenso.

Basándonos en los textos, precisemos un tanto ese signo:

1. Significa al vino; en ello están contestes todos los textos.

2. Significa al vino venal: se vende vino: lo especifican las citadas Summae Metenses, Bacon y Trutvetter.

3. Algunos textos se contentan con decir que es un signo; sin precisar qué tipo de signo sea: Summae Metenses y Suárez de Urbina.

4. No es un término. Se desprende de Ockham y Alberto de Sajonia, ${ }^{25}$ que ejemplifican con el círculo el sentido lato del signo. Y lo afirma expresamente Suárez de Urbina.

5. En cuanto se signifique a sí mismo, sería un signo natural: directamente lo dicen Bacon y Alberto de Sajonia. ${ }^{26}$

6. En cuanto signo del vino - al menos en los textos anteriores a Ockham- es signo convencional: De proprietatibus Sermonum: ${ }^{27}$ «En efecto, no todo el que ve el círculo capta al vino por medio del círculo, pero todo el que ve una pintura de un hombre capta un hombre». Es decir: la pintura no es signo convencional, precisamente porque se basa en semejanza y por eso mueve por sí al entendimiento a lo representado en ella. Pero sí el círculo, que significa en virtud de la propria industria del hombre, en virtud de convención; por eso es convencional. La Ars Meliduna: ${ }^{28}$ significa ex usu et discretione. y Bacon, que aduce el ejemplo a propósito de los signos convencionales.

7. En Ockham y Alberto: ${ }^{29}$ es signo en sentido amplio del mismo. Recordemos el texto completo de Ockham: $:^{30}$

24 «Línea circularis est perfectior quaelibet alia»: Sto. Tomás, Summa Contra Gentiles, 2.

25 Texto citado de la Perutilis Logica.

26 En las Quaestiones in Artem Veterem: «Circulus pendens ante tabernam non solum significat vinum, sed etiam significat seipsum»: ed. cit., n. 710 .

27 «Unde non omnis apprehendens circulum apprehendit vinum per circulum, sed omnis apprehendens picturam hominis apprehendit hominem»: ed. L. Rijk, Logica Modernorum, II-2, Assen, 1967, p. 710.

28 Ibid., II-1, p. 321.

29 Texto citado de Perutilis Logica.

30 «Signum dupliciter accipitur. Uno modo pro omni illo quod, apprehensum, aliquid aliud facit in cognitionem venire, quamvis non faciat mentem venire in primam cognitionem eius, sicut alibi est ostensum, sed in actualem post habitualem eius. Et sic vox naturaliter significat, sicut quilibet effectus significat saltem 
todo aquello que, al captarlo, nos lleva al conocimiento de algún otro, aunque no se trate del primer conocimiento de éste según lo hice ver en otro lugar, sino de un conocimiento actual, tras su conocimiento habitual. De este modo significa naturalmente la palabra al igual que todo efecto significa, al menos a su causa; y al igual también que el círculo significa al vino en la taberna. Pero aquí no hablo del signo en un sentido tan general.

Ockham (y Alberto) trae el ejemplo a propósito del signo en sentido amplio, no lingüístico. En las Sentencias acota que, en tal acepción, el signo se divide en imagen (basada en semejanza) y vestigio (causalidad). Pero Ockham distingue tres clases de vestigio: ${ }^{31}$

- sentido amplio: efecto dejado por una causa y que lleva al recuerdo de ella y a formar una proposición contingente sobre la misma; tomada aquí la causalidad unívoca o equívocamente; es un efecto ya sea causado propiamente o no. ${ }^{32} \mathrm{Ej} .:$ el humo, signo del fuego.

- sentido más restringido; efecto dejado por algo sobre otro, como impresión que permanece en ausencia del primero. Ej.: la impresión de un sello sobre la cera.

- sentido estricto: el anterior, pero producido por la parte de un todo sobre otro. Ej.: la huella dejada por un buey.

Creemos que, al redactar su Logica, posterior a las Sentencias, y querer puntualizar su noción de signo lógico, quiso puntualizar también la caracterización del ejemplo del círculo. Para los anteriores era un signo convencional; para él, un vestigio en sentido amplio con relación de causalidad no tan unívoca, con efecto no tan proprie causatum. Al hablar del signo en sentido amplio, ejemplifica: $:^{33}$

De este modo significa naturalmente la palabra, al igual que cada efecto significa al menos a su causa; y al igual también que el círculo significa al vino en la taberna.

En este sentido, la palabra - como mera voz- es signo natural. Pero Ockham pone al mismo nivel, equiparados en su valor de signo, el círculo y la palabra: son dos ejemplos de lo mismo, parece decir:

sic vox naturaliter significat

circulus vinum in taberna.

suam causam; sicut etiam circulus significat vinum in taberna»: ed. cit., pp. 8 s. El otro lugar de su obra al que alude Ockham es su Comentario In I Sententiarum, d. 3, q. 9, ed. Brown-Gál, St. Bonaventure, 1970, pp. 544 ss.

31 In I Sent., d. 3, q. 10, ed. cit. p. 548.

32 «Sive proprie causatum, sive non».

33 «Sic vox naturaliter significat, sicut quilibet effectus significat saltem suam causam; sicut etiam circulus significat vinum in taberna»: loc. cit. 
Pudo haber dejado así los ejemplos; pero quería aclarar definitivamente su opinión al respecto. Por eso recalcó:

sic vox naturaliter significat

sicut circulus vinum in taberna

Esto es: recordaba la noción de vestigio, Ockham ejemplifica: así, de este modo, significa la voz; igual que el círculo al vino. pero, temiendo que no quedara clara su caracterización del vestigio, insiste aún en su insitencia y prefiere decirnos:

sic vox naturaliter significat

sicut etiam circulus vinum in taberna

Igual que la palabra es signo de la causa que la profiere, así también (sicut etiam) el círculo lo es del vino; lo cual equivale a decir que aquél es signo natural de éste. Con lo que ha de pertenecer a la clase del signo vestigio.

Volvamos a la sugerida convergencia de significados del círculo verde y del vino, en la idea de excelencia y perfección sobresaliente. La euforia significada por el vino causa una pretendida perfección significada por el círculo verde. Avalarían esto los ejemplos de Suárez de Urbina, Trutvetter y Luis Vives, que manifestarían la tradición lógica (al menos desde Ockham) al utilizar el ejemplo. No es, es cierto, una causalidad propia, el vino causa del círculo, sino que la euforia, sublimación y superación represenadas por el vino causa la perfección representada por el círculo. En efecto, viridis significa «verde», pero también «vigoroso». Y sin necesidad de entender la rama de Suárez de Urbina como rama de vid (algo poco probable, como vimos) y que obligaría a una relación de causalidad (vid-vino, causa-efecto) inversa a la del signo natural (signo-significado, efecto-causa).

Así, habremos de concluir que Ockham aduce el círculo

- o (como se entendió hasta ahora) como ejemplo de signo (sentido amplio) convencional. Y la Summa completa lo dicho en las Sentencias, sobre el signo en sentido amplio. (Opción aceptable y concorde con la tradición lógica anterior). Es decir, que éste puede ser basado en:

- semejanza (imagen), p. ej., una estatua;

- causalidad (vestigio), p. ej., una huella;

- convención, p. ej., el círculo de la taberna, una bandera.

- o como ejemplo de signo (sentido amplio) no convencional basado en causalidad, un caso de vestigio. Así es equiparable al humo como signo del fuego, y a la palabra como signo de quien la profirió. Opción también aceptable y a nuestro entender más adecuada. El círculo (como la huella) nos trae el recuerdo de su significado, el vino, y una proposición contingente sobre ello: aquí se vende vino; pues es signo del vino venal, según precisan los textos aducidos. 
Se dirá que esto no altera demasiado la teoría del signo. Quizá sea verdad. Tras resolver la intriga que el ejemplo pudo producir, se trata de una puntualización que perfila la nueva visión de signo dada por Ockham, en el pórtico mismo de su Logica, y que tuvo bien cuidado de hacer propter protervos, a causa de los precipitados y sabelotodo.

Quizá todo lo anterior no pasó de un romanz, rizando el rizo, de un nuevo frustado intento de la cuadratura del círculo. A pesar de todo, y con la benevolencia del lector,

bien valdrá, según creo, un vaso de bon vino...

\author{
Ángel Muñoz García \\ Apartado 10114 \\ Maracaibo (Venezuela)
}

